\title{
Systematical assessment of cancer stemness traits via one-class logistic regression (OCLR) algorithm and associations with tumor immune infiltrates in prostate cancer based on seven cohorts
}

\section{Hongxi Chen}

Hunan Normal University

Jinliang Xie

Xiangya hospital

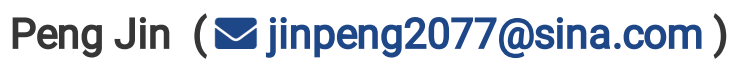

Central South University Xiangya School of Medicine https://orcid.org/0000-0003-4266-0034

\section{Primary research}

Keywords: stemness indices, mRNAsi, prognosis, immunosuppression, Connectivity Map, prostate cancer

Posted Date: August 26th, 2020

DOI: https://doi.org/10.21203/rs.3.rs-35734/v2

License: (c) (i) This work is licensed under a Creative Commons Attribution 4.0 International License.

Read Full License 
The authors have withdrawn this preprint from Research Square 